\title{
Instituições de Ensino Superior e Desenvolvimento Regional: O Caso da Região Norte do Paraná ${ }^{1}$
}

\author{
Cássio Rolim ${ }^{2}$ \\ Maurício Serra ${ }^{3}$
}

Resumo: As universidades sempre contribuíram para o desenvolvimento dos países. Entretanto, a preocupação com a sua contribuição para o desenvolvimento regional é recente e deriva de um intenso processo de globalização e também de um novo olhar sobre a competitividade das regiões e sobre os sistemas regionais de inovação. Nesse sentido, o engajamento das universidades com outros atores na região é esperado com o propósto de fornecer respostas às necessidades da região. O objetivo deste artigo é analisar o esforço cooperativo entre as IES (Instituições de Ensino Superior) da região Norte do Paraná e os seus parceiros regionais em prol do desenvolvimento regional.

Palavras-chave: Instituições de Ensino Superior; Desenvolvimento Regional; Sistema Regional de Inovação; Paraná.

\footnotetext{
1 Este artigo é resultado da pesquisa do IMHE/OECD (The Programme on Institutional Management in Higher Education/Organization for Economic Cooperation and Development), intitulada Supporting the Contribution of Higher Education Institutions to Regional Development, e que contou com auxílio da Secretaria de Ciência, Tecnologia e Ensino Superior do Estado do Paraná. Os autores agradecem às várias instituições participantes e às pessoas a elas ligadas, especialmente aos professores Antônio Carlos Lugnani (UEM) e Rossana Lott Rodrigues (UEL). Eventuais erros e omissões são de inteira responsabilidade dos autores.

2 Professor do Departamento de Economia e do Programa de Pós-Graduação em Desenvolvimento Econômico da Universidade Federal do Paraná (PPGDE/UFPR). E-mail: cassio.rolim@ufpr.br.

3 Professor do Departamento de Economia e do Programa de Pós-Graduação em Desenvolvimento Econômico da Universidade Federal do Paraná (PPGDE/UFPR). E-mail: serra@ufpr.br.
} 


\title{
Higher Education Institutions and Regional Development: The Case of Northern Paraná Region
}

\begin{abstract}
Universities have always contributed to the development of countries. However, the concern with their contribution to regional development is recent and derives from an intense globalization process and also from a new way of looking at the competitiveness of regions and at regional innovation systems. In this regard, the engagement of universities with others regional actors is expected in order to provide responses to regional needs. The objective of this article is to analyse the cooperative efforts between HEIs (Higher Education Institutions) in the northern Parana region and their regional partners in the quest of regional development.
\end{abstract}

Keywords: Higher Education Institutions; Regional Development; Regional Innovation System; Paraná.

JEL: I20; R10

\section{Introdução}

Este artigo teve origem na demanda da Secretaria de Ciência, Tecnologia e Ensino Superior do Estado do Paraná (SETI), que objetivava avaliar o impacto socioeconômico das instituições de ensino superior (IES) paranaenses. Nesse sentido, dois tipos de análise de impactos eram almejados: um de curto-prazo, que foi realizado com base numa literatura consagrada que utiliza a análise de insumo-produto e os modelos de equilíbrio geral computável (Rolim \& Kureski 2006) e o segundo de longo-prazo, objeto do presente artigo, sendo a sua realização baseada na metodologia específica da OCDE (Organização para Cooperação e Desenvolvimento Econômico), que foi desenvolvida para o seu projeto Supporting the Contribution of Higher Education Institutions to Regional Development (OCDE 2005).

A concepção básica que norteou projeto é de que a educação superior cumpre um papel relevante no processo de desenvolvimento econômico, cultural e social dos países e, principalmente, das regiões. De fato, a dimensão regional passa a ter uma importância capital na medida em que o ambiente regional/ local é tão importante quanto a situação macroeconômica nacional na determinação da habilidade das empresas em competir numa economia globalizada, ou seja, a disponibilidade dos atributos regionais/locais (conhecimento, habilidades, etc.) influirá fortemente na decisão locacional das empresas, $o$ que faz das universidades regionalmente engajadas peças-chave das regiões onde estão inseridas.

O objetivo deste artigo é analisar o esforço cooperativo entre as IES da região 
Norte do Paraná, considerando fundamentalmente as suas duas principais universidades estaduais, a UEL (Universidade Estadual de Londrina) e a UEM (Universidade Estadual de Maringá), e os demais atores regionais em prol do desenvolvimento regional, levando em consideração as barreiras internas e externas às universidades para concretizá-lo. Para tanto, o presente artigo está estruturado em cinco sessões, além desta introdução. A primeira faz um breve enquadramento teórico da questão, a segunda expõe o enfoque metodológico adotado, a terceira especifica o contexto paranaense, a quarta apresenta os principais resultados do estudo de caso e por fim, as considerações finais são tecidas na última sessão.

\section{Universidade e Região}

O papel das universidades no processo de desenvolvimento regional vem recebendo uma atenção crescente nos últimos anos e está sendo considerado como um elemento-chave deste processo. Nas últimas décadas, em função da compreensão de que as inovações têm um papel relevante no desenvolvimento econômico dos países houve uma preocupação crescente com os condicionantes dessas inovações, sendo esta a motivação para uma extensa literatura sobre o que é chamado de Sistema Nacional de Inovações, Economia do Conhecimento, etc. Em paralelo ocorreu um debate renovador sobre o desenvolvimento das regiões. A moderna concepção considera que as regiões com maior possibilidade de desenvolvimento são aquelas que conseguem estabelecer um projeto político de desenvolvimento congregando os seus diferentes atores, fazendo parte desse projeto, na sua vertente econômica, a utilização intensiva e coordenada do conjunto de conhecimentos existentes na região para aumentar a sua competitividade.

O encontro dessas duas vertentes dá origem ao conceito de Sistema Regional de Inovação. As primeiras referências ao termo surgiram no início dos anos noventa e o referencial teórico para este conceito pode ser encontrado principalmente nos trabalhos de Cooke (1997, 1998a, 1998b).

Segundo Cooke \& Morgan (1998:71), o atual estágio de desenvolvimento do conceito de Sistema Regional de Inovação pode ser assim sintetizado:

As regiões que possuem o conjunto ideal de organizações para a inovação inseridas em um meio institucional adequado (Johnson \& Gregersen, 1996; Maillat, 1995) onde ligações sistêmicas e comunicação interativa entre os atores da inovação é um fato normal, enquadram-se na designação de sistema regional de inovação. A expectativa é que esse conjunto de organizações seja constituído de universidades, laboratórios de pesquisa básica, laboratórios de pesquisa aplicada, agencias de transferencia de tecnologia, organizações regionais de governança, públicas e privadas, (p.ex., associações comerciais, câmeras de comercio), organizações de treinamento vocacional, bancos, empresários dispostos a desenvolver novos produtos em parcerias de risco, pequenas e grandes empresas interagindo. 
Além disso essas organizações devem demonstrar vínculos sistêmicos através de programas em comum, participação conjunta em pesquisa, fluxos de informações e pelo estabelecimento de linhas de ação política pelas organizações de governança. Esses são sistemas que combinam aprendizado com capacidade de inovação, "upstream" e "downstream", e que merecem, portanto, a designação de sistemas regionais de inovação.

Nesta síntese, pode-se ver a existência de vários subsistemas correlatos na constituição de um Sistema Regional de Inovação (ver Figura 1). Entre os mais importantes, encontram-se os subsistemas financeiros e de aprendizado e um outro subsistema, relacionado a cultura voltada para a produção. Sem o primeiro, as possibilidades de inovação ficam muito reduzidas, particularmente para estruturas regionais em que predominam as pequenas e médias empresas. O sistema de aprendizado é fundamental, uma vez que as restrições ao seu funcionamento significam restrições de acesso ao conhecimento acumulado e, portanto, a anulação da possibilidade de gerar algum tipo de inovação (Cooke et al. 1997). Finalmente, a cultura produtiva, que significa o grau de envolvimento local com as atividades que se desenrolam na região, está relacionada ao ambiente e às atitudes voltadas para essas atividades e, portanto, decorrem da existência de uma mentalidade empresarial e de uma cultura técnica inerente aos habitantes da região, que é advinda da transmissão de conhecimentos e saberes, passados de pai para filho. Isso pode ser expresso pelos conceitos de milieu e milieu inovateur desenvolvidos no âmbito do GREMI - Groupe de Recherche Européen sur les Milieux Innovateurs (Maillat 1994).

\section{UNIVERSIDADES E REGIÃO ENQUADRAMENTO DA QUESTÃO}

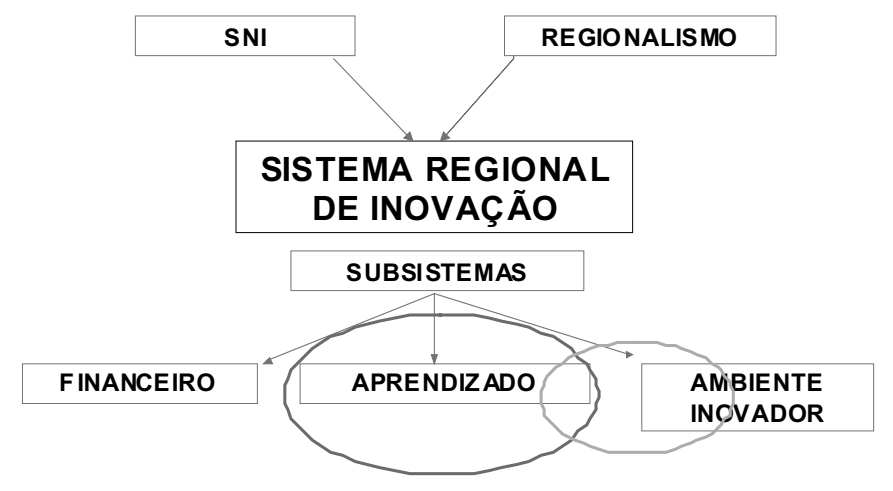

FIGURA 1

Fonte: Elaboração própria. 
Essa literatura acentua as particularidades dos sistemas regionais de aprendizado, integrante de um sistema regional de inovação porque o aprendizado é o ponto de partida para a inovação. De fato, o aprendizado significa uma mudança na capacitação de uma pessoa ou de uma organização, isso porque esse aprendizado é concebido não só como um acréscimo de informações, mas também, e numa perspectiva piagetiana, como um processo de interação entre o que se sabe sobre uma determinada situação e o que se pode perceber como novo nessa situação.

Nesse sentido, é perfeitamente possível distinguir, em termos de formação do conhecimento, dois níveis de aprendizado: o primeiro seria aquele que fornece a competência (habilidade para realizar uma tarefa específica) e o segundo aquele que provê a capacitação (compreensão dos mecanismos subjacentes à solução do problema envolvido na tarefa). Na medida em que esse sistema regional de aprendizado interaja, formal ou informalmente, com universidades, institutos de pesquisa, agências de treinamento vocacional, transferência de tecnologia, parques tecnológicos, e também com as empresas em geral, ele tende a se transformar em um Sistema Regional de Informação (Cooke \& Morgan 1998).

É dentro dessa perspectiva que se insere a adequação das universidades para desempenhar um papel determinante no processo de desenvolvimento regional, sendo possível distinguir duas trajetórias claras: a universidade que está na região e a que é da região. Na primeira, a universidade simplesmente se localiza na região, se caracteriza por um reduzido número de vínculos e compromissos com a região e com o seu desenvolvimento e o produto do seu trabalho está direcionado para o contexto nacional e/ou internacional. Já na segunda trajetória, a universidade demonstra ter um forte impacto no processo de desenvolvimento regional, estabelece vínculos e compromissos intensos com o futuro da região e o produto do seu trabalho, além de ter como referência a qualidade acadêmica universal, está voltado para a superação das questões da região. Essa distinção entre ser e estar na região faz toda a diferença para o desenvolvimento regional.

\section{Procedimentos Metodológicos}

Torna-se importante salientar que toda a metodologia aplicada na região norte do Paraná, objeto de estudo do presente artigo, foi desenvolvida pela OCDE (2005) e consistiu de cinco etapas. A primeira delas foi a apresentação aos membros das IES da região norte paranaense e aos atores regionais do que iria ser realizado. Para isso, foram feitos seminários em Londrina e Maringá com a presença de membros da UEL e da UEM e dos atores regionais pertencentes ao setor produtivo, políticos, representantes das instituições de ensino superior privadas e demais representantes da sociedade civil organizada. 
Na segunda etapa foram coletadas informações pelas próprias universidades em um exercício de auto-diagnóstico. Para tanto, foi aplicado um questionário baseado na metodologia da OCDE (2005), cujas informações serviram de base para o relatório final sobre a região norte do Paraná (Rolim et al. 2006). A terceira etapa resumiu-se à visita feita pelos coordenadores aos atores regionais representativos, que foram previamente indicados pelos coordenadores de grupos de trabalho das duas universidades estaduais, UEL e UEM, da região estudada. As entrevistas realizadas tinham como objetivo conhecer as expectativas e as experiências já vivenciadas desses atores com relação às referidas universidades.

A quarta etapa teve como foco central a realização de workshops na UEL e na UEM com a participação de membros da academia e da comunidade regional trabalhando em uma análise SWOT (pontos fracos, pontos fortes, desafios e oportunidades), a partir dos principais pontos do questionário preenchido pelas IES da região, sendo que ambos os workshops foram conduzidos com o apoio do SEBRAE. Por fim, a última etapa consistiu na redação do relatório elaborado pela coordenação do projeto, o qual foi enviado aos coordenadores dos grupos de trabalho nas IES e, através deles, aos demais atores regionais. Este relatório foi o documento que serviu de embasamento para a visita da missão de especialistas da OCDE.

Na realidade, essa metodologia da OCDE procurou responder às seguintes questões: 1) contribuição da pesquisa à inovação regional, que incluia três itens: resposta às demandas e necessidades regionais; condições estruturais para promover a pesquisa e a inovação; e processos facilitadores da transmissão e aproveitamento do conhecimento; 2) contribuição do ensino e aprendizado ao mercado de trabalho e à profissionalização, que abrangia os seguintes tópicos: territorialização do processo de aprendizagem; atração de estudantes e emprego regional; promoção de educação contínua, treinamento e aperfeiçoamento profissional; formas alternativas de ensino; e otimização do sistema regional de aprendizagem; 3) contribuição ao desenvolvimento social, cultural e ambiental, em que três aspectos eram abordados: desenvolvimento social; desenvolvimento cultural; e a sustentabilidade ambiental; 4) capacitação para a cooperação regional, que incorporava seis preocupações: mecanismos para promover o envolvimento universidade-região; promoção conjunta do diálogo e iniciativas de interesse regional; avaliação e mapeamento do impacto da universidade; capacitação institucional para o envolvimento regional; gerenciamento dos recursos humanos e financeiros; e criação de uma nova cultura organizacional; e 5) as conclusões, ou seja, o aprendizado com a auto-avaliação, que continha os seguintes itens a serem respondidos: que práticas e metodologias são mais promissoras para melhorar a capacitação regional e que fatores contribuem para o seu sucesso?, que sinergia existe entre os objetivos da universidade e da região? existe conflito de interesses?, que incentivos existem ao nível institucional, setorial, departamental, individual para um maior engajamento?, quais os principais desafios colocados para 
os diferentes tipos de tomadores de decisão?, potencialidades, problemas, oportunidades e ameaças para aumentar a contribuição da universidade para o desenvolvimento da região, e a possibilidade de as IES tornarem-se o fórum para a elaboração de uma estratégia política para a região.

\section{O Contexto Parananse e a Região Norte}

O estado do Paraná se localiza na região sul do país e faz fronteira ao norte com o estado de São Paulo; ao sul com Santa Catarina; a noroeste com Mato Grosso do Sul; a oeste com o Paraguai; e a sudoeste com a Argentina. O seu território abrange $199.554 \mathrm{~km}^{2}$, o que corresponde a dois terços do tamanho da Itália ou a 2,35\% do território brasileiro, e o seu PIB equivale a $6 \%$ do PIB brasileiro.

A população paranaense tem 9.563 .458 habitantes, o que equivale a $5,45 \%$ da população brasileira, e se concentra predominantemente na Região Metropolitana de Curitiba (RMC), cujo principal pólo urbano é a cidade de Curitiba. O PIB da RMC, devido ao grande afluxo de investimentos privados capitaneados pela indústria automobilística, cresceu a taxas elevadas ao longo da última década e representa atualmente cerca de $38 \%$ do PIB do Paraná. Já a mesorregião Norte Central, que é o objeto do presente estudo, representa cerca de $16 \%$ do PIB estadual.

O Paraná tem uma história de colonização recente. No século XVI, nos primórdios da colonização brasileira, a ocupação populacional era restrita apenas ao litoral paranaense e à região em que hoje se encontra a capital do estado. A ocupação intensiva da região norte paranaense ocorreu somente a partir de 1940 e foi em decorrência da expansão do cultivo do café em São Paulo. De fato, a cafeicultura, de meados do século XIX, foi o motor do desenvolvimento deste estado da federação. Até um passado recente, o norte do Paraná foi uma das áreas mais prósperas do estado. A ocupação do sudoeste paranaense só foi iniciada na segunda metade do século passado como resultado dos fluxos migratórios provenientes do Rio Grande do Sul, onde ainda prevalecia uma agricultura familiar baseada na subsistência.

Com efeito, o povoamento do Paraná se deu a partir de três diferentes frentes de ocupação, provenientes de diferentes partes do Brasil, cada qual em seu momento histórico específico. Tal fato gerou um problema complexo para a administração estadual, pois em várias ocasiões houve tentativas de emancipação em diferentes partes do território paranaense. Em outras palavras, a maneira pela qual a ocupação foi efetivada acabou por ser um fator contrário à emergência de uma identificação territorial. Na realidade, a ocupação populacional historicamente se efetivou em oposição à própria coesão e identidade do estado. 
Em geral, o Paraná tem sido caracterizado como um estado agrícola. No decorrer dos últimos quinze anos, emergiu no estado um dos mais modernos sistemas agrícolas do país. Sendo o Brasil uma potência agrícola, com níveis de produtividade que se tornaram padrão internacional de referência, podese afirmar que o Paraná possui um dos setores agrícolas mais dinâmicos do mundo. Por outro lado, o processo de industrialização de Curitiba, assim como das cidades que constituem sua região metropolitana, ocorreu a partir dos anos setenta. Iniciando-se em setores tradicionais, ligados à produção madeireira e alimentícia, este processo evoluiu para setores mais dinâmicos e modernos, com ênfase na indústria metal-mecânica e de materiais elétricos e eletrônicos. Estas novas indústrias foram, em termos gerais, extensões de empresas nacionais e multinacionais que se expandiram a partir da região metropolitana de São Paulo. Alguns bons exemplos podem ser citados como o caso da Volvo, que se instalou na RMC nos anos setenta, e de outras empresas que consolidaram o pólo automobilístico da região nos anos noventa, tais como a Renault e a Audi-VW. Além de fatores locais de atração, a política expansionista de incentivos fiscais implementada pelo governo paranaense foi um fator importante para a industrialização da RMC.

Uma síntese do estado do Paraná poderia caracterizá-lo pela coexistência de dois grandes espaços econômicos: um sob a égide do agronegócio e outro sob a égide da economia urbano-industrial (Rolim 1996).

Especificamente em relação à região Norte do Paraná, não há um claro consenso a seu respeito. Pode-se dizer, no entanto, que ele está centrado dinamicamente no eixo Londrina-Maringa, englobando uma vasta área que engloba pelo menos três mesoregiões: Noroeste do Paraná; Norte Central do Paraná; e Norte Pioneiro do Paraná. A mais importante delas é a do Norte Central. Trata-se da segunda mais importante região paranaense, uma vez que depois de Curitiba, as duas principais cidades do estado - Londrina e Maringá - encontram-se nesta região. Nestas cidades, respectivamente, localizam-se as maiores universidades estaduais do Paraná: a UEL e a UEM.

A Mesorregião do Norte Central organiza-se ao longo de um eixo de $120 \mathrm{~km}$ que liga as cidades de Londrina e Maringá. Constitui-se em um pólo de atração de outras áreas da região norte do Paraná e de áreas vizinhas do estado de São Paulo e do Mato Grosso do Sul. A população concentrada nesta área é de mais de três milhões de habitantes.

Apesar da importância da região Norte do Paraná como um todo, este estudo se detém na análise de Londrina e Maringá, as principais cidades do Norte Central. Reunidas, elas possuem uma área de $24.419 \mathrm{~km}^{2}$. Nos anos setenta, o Norte Central chegou a possuir mais de $25 \%$ do total do valor adicionado do Paraná. Atualmente, possui apenas 15\%. A razão para a perda de importância relativa na economia do estado foram as altas taxas de crescimento industrial da Região Metropolitana de Curitiba que emergiu como um importante lócus 
do processo de descentralização da industrialização brasileira ${ }^{4}$. Contudo, o Norte Central, em termos absolutos, e devido à forte expansão da sua produtividade agrícola, vem apresentando bons níveis de desenvolvimento econômico nos últimos anos, ainda que o dinamismo do passado tenha se arrefecido um pouco (ver Tabela 1).

TABELA 1 - MESORREGIÕES DO PARANÁ, INDICADORES SELECIONADOS, 2000.

\begin{tabular}{|c|c|c|c|c|c|c|}
\hline Mesorregiões & $\begin{array}{c}\mathrm{N}^{0} \text { de } \\
\text { Municípios }\end{array}$ & $\begin{array}{l}\text { População } \\
\text { Total }\end{array}$ & $\begin{array}{c}\text { Taxa de } \\
\text { Crescimento } \\
\text { Populacional, } \\
\text { 1991-2000 }\end{array}$ & $\begin{array}{c}\text { Grau de } \\
\text { Urbanização }\end{array}$ & $\begin{array}{c}\text { Participação } \\
\text { no Valor } \\
\text { Adicionado } \\
\text { Fiscal do } \\
\text { Estado }\end{array}$ & $\begin{array}{c}\text { Taxa de } \\
\text { Desemprego } \\
\text { (\%) }\end{array}$ \\
\hline Noroeste & 61 & 641.084 & $-0,25$ & 77,3 & 3,7 & 10,7 \\
\hline $\begin{array}{l}\text { Centro } \\
\cdot \text { Ocidental }\end{array}$ & 25 & 346.648 & $-1,24$ & 72,6 & 2,2 & 13,7 \\
\hline Norte Central & 79 & 1.829 .068 & 1,24 & 88,4 & 14,3 & 12,4 \\
\hline $\begin{array}{l}\text { Norte } \\
\text { Pioneiro }\end{array}$ & 46 & 548.190 & $-0,15$ & 75,1 & 2,8 & 11,9 \\
\hline $\begin{array}{l}\text { Centro- } \\
\text { Oriental }\end{array}$ & 14 & $623 \cdot 356$ & 1,46 & 81,2 & 7,6 & 14,1 \\
\hline Oeste & 50 & 1.138 .582 & 1,28 & 81,6 & 13,8 & 12,8 \\
\hline Sudoeste & 37 & 472.626 & $-0,13$ & 59,9 & 3,5 & 8,4 \\
\hline Centro-Sul & 29 & $533 \cdot 317$ & 0,69 & 60,9 & 3,9 & 11,5 \\
\hline Sudeste & 21 & 377.274 & 0,89 & 53,6 & 2,3 & 9 \\
\hline $\begin{array}{l}\text { Metropolitana } \\
\text { de Curitiba }\end{array}$ & 37 & 3.053 .313 & 3,13 & 90,6 & 45,9 & 14,7 \\
\hline Paraná & 399 & 9.563 .458 & 1,4 & 81,4 & 100 & 128 \\
\hline
\end{tabular}

Fonte: elaboração própria com dados do IBGE (2000) e IPARDES (2004).

Esta área foi colonizada e desenvolvida por intermédio da cafeicultura. As condições climáticas adversas provocaram uma grande quebra da safra de café na metade dos anos setenta e as plantações de café quase desapareceram da região. A substituição por outras culturas agrícolas, sobretudo por plantações de soja e pela pecuária, tornou o Norte Central um dos mais importantes pólos agrícolas do Brasil. A região, principalmente o eixo Londrina-Maringá, apresenta uma notável tradição de organização em grandes cooperativas agrícolas e também lá se encontra a segunda maior concentração industrial do Paraná. Essas indústrias estão estreitamente ligadas ao agronegócio e aos mercados urbanos, predominando as atividades relacionadas aos segmentos moveleiro, têxtil, alimentício, plástico e mecânico, entre outros. É importante ressaltar que o setor de serviços vem se tornando o principal setor do eixo Londrina-Maringá, dada a sua crescente urbanização.

Comparando o Norte Central com a mesorregião Metropolitana de Curitiba é possível verificar que ambas possuem alto nível de urbanização. Entretanto,

4 Quase 65\% do valor adicionado fiscal pelo setor industrial paranaense é gerado pela RMC, ao passo que a região do Norte Central contribui com 11,6\%. 
esta última mesorregião possui mais de $30 \%$ da população do estado (ver tabela 1). Em relação à participação da população ocupada, os dados são similares à participação no total da população do Paraná, mas a diferença mais significativa reside na participação da mesorregião Metropolitana de Curitiba na economia estadual (considerando o Valor Adicionado Estadual). O peso relativo desta última mesorregião é quase quatro vezes o da Norte Central, sendo outro aspecto importante de ser sublinhado a sua elevada taxa de urbanização.

A região Norte Central está a cerca de $600 \mathrm{~km}$ da cidade de São Paulo e a mais de $1.500 \mathrm{~km}$ de Brasília. Há uma boa rede de rodovias e também tanto Londrina como Maringá tem vôos regulares para as principais cidades do país. Em cerca de uma hora de vôo é possível chegar aos aeroportos internacionais de São Paulo e/ou no Rio de Janeiro, o que as torna cidades conectadas com o Brasil e o resto do mundo.

\section{As Universidades e o Norte do Paraná ${ }^{5}$}

As universidades da região norte do Paraná, especificamente a UEL e a UEM, têm uma estreita ligação com a região, sendo o desenvolvimento desta, em grande medida, fruto da ativa participação delas nos problemas regionais. Embora esta participação seja visível, ainda há muito a ser feito. De fato, as relações entre as universidades estaduais do norte paranaense e a sociedade civil precisam ser mais estimuladas de modo que as restrições de ambas as partes possam ser superadas, o que favoreceria, de um modo geral, a todos e as atividades produtivas em particular, uma vez que estas necessitam cada vez mais de capital humano qualificado (os alunos formados) e das pesquisas e inovações desenvolvidas na academia.

Tanto a UEL quanto a UEM estão abertas à sociedade, uma vez que os seus espaços podem ser utilizados pela população local, há uma considerável promoção de atividades culturais, e cursos e programas são oferecidos para os diversos segmentos sociais. Entretanto, estas universidades, apesar de todo o progresso feito nas últimas décadas, estão muito longe do nível alcançado pelas universidades dos países desenvolvidos e do que elas mesmas, com poucas mudanças, podem oferecer.

\subsection{Práticas e Metodologias Promissoras para o Fortalecimento} da Capacidade de Construção Regional

Apesar do vínculo das universidades com a região e do fato delas serem as mais importantes e pujantes universidades públicas estaduais, a estrutura voltada para a pesquisa e o desenvolvimento (P\&D) e a inovação pode ser considerada 
ainda incipiente na medida em que elas ainda estão distantes da realidade das melhores universidades brasileiras e, principalmente, estrangeiras. Embora essas restrições sejam uma realidade, há um grande volume de conhecimento acumulado que não consegue chegar aos potenciais utilizadores.

Dentro deste contexto, algumas práticas ou metodologias parecem promissoras no sentido de que elas parecem estimular uma nova cultura voltada para o desenvolvimento regional e que está assentada na parceria entre universidade e setor produtivo. Embora ainda existam vários obstáculos a serem superados, é notório o esforço da UEL e da UEM em estreitar os laços com as empresas e, ao mesmo tempo, mostrar claramente para o meio que as cerca o que se faz e produz dentro da academia. As incubadoras tecnológicas, o Escritório de Negócios, por exemplo, são iniciativas dessas universidades para fomentar a cooperação com o mundo empresarial e os resultados, ainda que tímidos, começam a aparecer e, por conseguinte, a sinalizar que os canais de ligação entre universidade e setor produtivo podem e devem ser ampliados.

Um aspecto importante de ser salientado, e que está relacionado ao comentário acima, é a necessidade das universidades promoverem um melhor intercâmbio com a sociedade civil de modo que esta fique ciente não só da sua importância como do seu potencial de P\&D em prol do desenvolvimento regional. Além da "conscientização" do meio que as cercam para o que é realizado no mundo acadêmico, é preciso também que as universidades tenham iniciativas para participar e acompanhar o que acontece no setor produtivo, sendo os parques tecnológicos um bom exemplo, uma vez que há a possibilidade de um maior entrelaçamento de acadêmicos com empresários.

Ambas as universidades têm um bom desempenho no que tange aos aspectos culturais. Neste sentido, vários tipos de cursos e eventos são oferecidos para toda a sociedade. Há a participação de integrantes da comunidade, de professores, de alunos e de técnico-administrativos da universidade tantos nos eventos quanto nos cursos, que costumam ter uma expressiva participação da sociedade.

4.2 Sinergias Existentes e Conflitos de Interesse entre as Intenções e os Objetivos das Instituições e da Região

Toda região almeja alcançar um elevado padrão econômico, social e cultural em que a sua população residente possa desfrutar de uma excelente qualidade de vida. Por sua vez, as universidades estão, de um modo geral, centradas em objetivos estritamente acadêmicos. Embora os propósitos de regiões e 
universidades sejam distintos, estas últimas certamente podem contribuir para a melhoria do patamar de vida de sua região através do que elas têm de melhor a oferecer: a qualidade dos profissionais que elas formam, as pesquisas desenvolvidas em seus campi e a transferência dos seus resultados para a sociedade. Além disso, elas também podem fornecer ao meio que a cerca uma ampla variedade de atividades culturais, que acabam por fazer parte do calendário cultural promovido pela municipalidade.

As sinergias entre as intenções e os objetivos das universidades do Norte do Paraná e da região são visíveis. Entretanto, essas sinergias não são lineares, ou seja, há freqüentemente dissonância entre as universidades, os governos e os demais atores regionais, na medida em que as primeiras se pautam basicamente por critérios acadêmicos, ao passo que os segundos são guiados por interesses políticos e os demais, em especial os vinculados às atividades econômicas, pautam-se pela lógica do mercado. Na realidade, as universidades dependem bastante de verbas estaduais e federais, o que vem a ser uma severa restrição para a uma atuação mais abrangente e independente na sua própria região. No entanto, se as sinergias são visíveis nos discursos, a sua praxis é muito difícil.

4.3 Os Incentivos para um maior Comprometimento das IES com a Região

Um dos grandes problemas para o engajamento das IES na região é a falta de incentivos para essa prática. Na realidade, esse não é um problema restrito às universidades estaduais paranaenses na medida em que ele está presente na maioria das universidades públicas brasileiras. O quadro institucional vigente a partir da legislação e das instituições federais não traz incentivos às inserções regionais. As instituições nacionais de fomento têm como critério de seleção e concessão de bolsas e financiamentos a excelência acadêmica segundo padrões internacionais. O mesmo acontece com a maioria dos editais de concursos de propostas de pesquisa. Raramente eles contemplam a possibilidade de tratamento de questões regionais.

Dentro do Paraná, a legislação e as instituições também agem de forma semelhante. As pesquisas desenvolvidas na região são, em grande parte, financiadas pelo governo estadual, através da Fundação Araucária e da UGF (Unidade de Gestão Financeira), sendo ambas subordinadas à SETI. Esses recursos, além de escassos, são aplicados em função de uma diretriz política, que é temporária e que muitas vezes está divorciada dos reais interesses e necessidades da própria região. Os editais de convocação para propostas de pesquisa nem sempre trazem como prioridade o tratamento das questões especificamente regionais. Por outro lado, muitos órgãos públicos e instituições de pesquisa do estado tendem a contratar consultores e instituições de pesquisa pertencentes a universidades de fora do estado. 
Ao adotarem essas políticas, as instituições também contribuem para o desincentivo ao estudo de questões regionais pelas universidades paranaenses e para a dificuldade da formação de capacity building no Paraná.

Os recursos estaduais destinados às universidades, por sua vez, estão relacionados a uma série de fatores específicos, tais como o número de alunos, de professores e pesquisadores, cursos oferecidos, etc., que não tem nada a ver com as questões regionais. De fato, não há qualquer tipo de incentivo para que professores e pesquisadores insiram ou adotem a temática regional em suas atividades acadêmicas, sendo importante destacar que as próprias universidades estaduais, especificamente a UEL e a UEM, não estimulam que seu staff incorpore esta prática.

4.4 Os Desafios Enfrentados pelos Diferentes Atores da Região

O principal desafio a ser enfrentado pelo conjunto de diferentes atores regionais está na formação de um consenso a respeito dos problemas e do futuro da região. Embora existam os conselhos de desenvolvimento nas cidades de Londrina e Maringá, que funcionam com autonomia e relativamente sem grandes entraves, eles não estão suficientemente instrumentalizados para conceber um plano de desenvolvimento que atenda as necessidades da região e que esteja em sintonia com o próprio plano de desenvolvimento das universidades. Na realidade, as diferentes "percepções de mundo", das universidades e do setor produtivo, são obstáculos reais que precisam ser vencidos para que todos ganhem, principalmente a região.

Outro desafio, que está intrinsecamente relacionado ao anterior, é o das universidades assumirem o papel de liderança no processo de desenvolvimento regional, ainda que possa ser questionado se essa é uma tarefa da universidade, ela poderia ter pelo menos uma participação mais efetiva nesse processo. De ato, embora elas participem dos conselhos de desenvolvimento, dos institutos de tecnologia, das associações de municípios e de programas de desenvolvimento de suas regiões, o seu papel no processo de desenvolvimento regional ainda está muito aquém do que poderia ser. Obviamente que o excesso de burocracia e os impedimentos da legislação universitária são barreiras significativas, mas existe também certa comodidade inerente ao universo acadêmico que torna a participação das universidades junto à sociedade mais difícil.

Desafios importantes também estão presentes na área de formação de profissionais. Embora as universidades estejam pautadas por valores universais na elaboração de currículos e na criação de cursos, elas não têm informações precisas sobre o que a região espera de seus alunos, qual o destino dos alunos formados, qual setor de atividades em que trabalham e em 
que lugar residem. Os cursos são criados e os currículos são reformulados sem que haja uma investigação profunda sobre a demanda que existe sobre esses conhecimentos. Também vinculado a esse desafio maior está a ampliação da oferta de formação contínua para os profissionais já formados.

A disponibilização dos conhecimentos já acumulados nas universidades e o direcionamento de pesquisas para as necessidades regionais é, também, um grande desafio para as universidades. Talvez a maior dificuldade resida justamente na solução dos problemas de comunicação com os usuários. A grande questão a ser respondida é: como fazer chegar ao empresário típico da região os conhecimentos acumulados na universidade que podem aumentar a sua competitividade?

Finalmente, um desafio significativo a ser enfrentado tanto pelas universidades como pelas autoridades governamentais é a mudança da cultura interna em ambas as esferas, uma vez que a liberdade e o incentivo para que o corpo docente busque complementações salariais são aspectos relevantes. Um sistema que remunerasse os professores pelas tarefas efetivamente realizadas e os deixasse livres para buscar complementação salarial através de pesquisas, consultorias e cursos de curta duração ao invés de uma remuneração única, provavelmente traria maior interação com a região.

\section{Considerações Finais}

O impacto das universidades sobre as regiões em que elas estão inseridas é sempre um processo inacabado de longo prazo. Assim sendo, a avaliação do impacto da UEL e da UEM sobre o Norte do Paraná não tem uma resposta definitiva. Ainda que na maioria dos seus aspectos eles apresentem sinais positivos, este é um processo sempre em elaboração. As políticas que estão sendo elaboradas e implementadas para a região têm como pressuposto fundamental a idéia de que a pesquisa, o desenvolvimento e a inovação serão elementos-chave para o desenvolvimento regional. Os Parques Tecnológicos são vistos como potenciais alavancas para a economia regional e essas iniciativas tem tido o suporte de todos os atores, principalmente as universidades.

Cabe aqui sublinhar que os conselhos e as agências municipais de desenvolvimento foram o fórum de discussão destas políticas, tendo as universidades um papel colaborativo e não de liderança, conforme foi destacado anteriormente. Embora o governo estadual, através da SETI e do TECPAR, esteja apoiando estas iniciativas, ele não as concebeu e, portanto, elas não fazem parte de uma deliberada estratégia governamental de desenvolvimento para a região. Os agentes líderes desse processo têm sido as autoridades e os atores locais. $\mathrm{Na}$ 
realidade, os Parques Tecnológicos podem não só contribuir para o desenvolvimento regional, como também servir para que as universidades e o setor produtivo possam estreitar os laços e superar os preconceitos existentes em ambos os lados no que se refere a um trabalho em conjunto.

Outra dimensão, nem sempre colocada como prioritária pelos formuladores de política, é a formação do capital humano regional. Segundo Lundvall (2002), a maior contribuição das universidades é a qualidade do profissional que elas disponibilizam para a comunidade. Assim sendo, aprofundar a percepção de quais são os conhecimentos e habilidades necessários para a região será fundamental para o aperfeiçoamento da formação propiciada pelas universidades. Também aqui, a explicitação dessas necessidades requer um esforço de todos os atores regionais.

Será muito difícil, face ao quadro atual, que as universidades assumam a liderança na formulação de um projeto de desenvolvimento para a região. Isso, como vem sendo salientado, está nas mãos das lideranças locais. As universidades têm participado do processo, mas as estratégias em elaboração precisam ser explícitas no que se espera concretamente das universidades como formadoras de capital humano da região e como produtoras e difusoras do conhecimento que irá favorecer o aumento da produtividade e, conseqüentemente, da competitividade do aparelho produtivo regional. Nunca é demais lembrar que os principais atores regionais - as universidades, as lideranças políticas, os produtores, demais atores - são regidos por lógicas diferentes. A construção de regiões é, no entender de Boisier (1992), uma arte difícil e está em sintonia com estas distintas lógicas para se construir um projeto concreto de desenvolvimento voltado para a região.

\section{Referências}

BOISIER, Sergio E. (1992). El dificil arte de hacer region: las regiones como actores territoriales del nuevo orden internacional. Cusco: CBC.

COOKE, P.; URANGA, M.; ETXEBARRIA, L. (1977). "Regional innovation systems: institutional and organizational dimensions". Research Policy 26: 475-491.

COOKE, P.; BRACZYK, H-J.; HEIDENREICH, M. (1998). Regional innovation systems: the role of governances in a globalized world. London: UCL Press.

COOKE, P.; MORGAN, K. (1998). The associational economy: firms, regions and innovation. London: Oxford University Press.

IBGE (2000). Censo Demográfico. Rio de Janeiro: IBGE.

IPARDES (2004). Leituras Regionais. Curitiba: IPARDES.

LUNDVALL, Bengt-Ake (2002). “The university in the learning economy”. DRUID working paper n. 02-6, Aalborg: Aalborg University.

OCDE (2005). Aide-memoire for regions participating in the OCDE project Sup- 
ROLIM, C.; SERRA, M. Instituições de Ensino...

porting the Contribution of Higher Education Institutions to Regional Development. Paris: OCDE.

OCDE (2007). Higher education and regions: globally competitive, locally engaged. Paris: OCDE.

PNUD; IPEA; FJP (2003). Atlas do Desenvolvimento Humano no Brasil. Brasília: PNUD.

ROLIM, Cássio (1996). “O Paraná urbano e o Paraná do agrobusiness: as dificuldades para a formulação de um projeto politico". Revista Paranaense de Desenvolvimento, 86: 49-99.

ROLIM, C.; KURESKI, R. (2006). "Impacto econômico de curto prazo das Universidades Estaduais Paranaenses”. Relatório de pesquisa apresentado à Secretaria de Ciência, Tecnologia e Ensino Superior do Estado do Paraná.

ROLIM, C.; SERRA, M.; LUGNANI, A.; RODRIGUES, R. (2006). "Self-Evaluation Report: Northern Parana, Brazil”. Relatório apresentado à OCDE-IMHE como parte do projeto Supporting the Contribution of Higher Education Institutions to Regional Development.

Submissão: 27 de março 2008. Primeira resposta: 28 de abril de 2008. Aceite: 20 de fevereiro de 2009. 